\title{
EFFECTS OF GENOTYPE-BY-ENVIRONMENT INTERACTION ON THE MAIN AGRONOMIC TRAITS OF MAIZE HYBRIDS
}

\author{
Yue, H. W. ${ }^{1}$ - WANG, Y. B. ${ }^{2}$ - WeI, J. W. ${ }^{1}$ - Meng, Q. M. ${ }^{2}-$ YAng, B. L. ${ }^{3}$ - Chen, S. P. ${ }^{1}-$ XIE, \\ J. L. ${ }^{1}-$ PENG, H. C. ${ }^{1}-$ JIANG, X. W. ${ }^{4 *}$ \\ ${ }^{1}$ Dryland Farming Institute, Hebei Academy of Agriculture and Forestry Sciences, Hebei \\ Provincial Key Laboratory of Crops Drought Resistance Research, Hengshui 053000, China \\ ${ }^{2}$ Institute of Cereal and Oil Crops of Hebei Academy of Agriculture and Forestry Sciences, \\ Shijiazhuang 050051, China \\ ${ }^{3}$ Hebei Banghao Agricultural Development Co., Ltd., Shijiazhuang 050051, China \\ ${ }^{4}$ College of Agronomy, Qingdao Agricultural University, Qingdao 266109, China
}

(Received $16^{\text {th }}$ Sep 2019; accepted $4^{\text {th }}$ Dec 2019)

\begin{abstract}
The additive main effects and multiplicative interaction (AMMI) model and genotype main effects and genotype-by-environment interaction (GGE) biplot are commonly used to analyze multi environmental trial data. This study adopted the AMMI model and GGE biplot to comprehensively analyze the data on genotypes tested in the 2016-2017 Zhongcheng combined regional maize trial in China. Results showed that the traits highly and significantly differed across different genotypes $(\mathrm{G})$ and environments (E). Significant or very significant genotype-by-environment interactions (GEI) were also found. With the exception of 100-kernel weight, the ratio of GEI for the remaining three traits was lower than that of E and higher than that of G. GEI was decomposed, and the interaction information of PCA1 and PCA2 in the interaction of four traits was significant. Hengyu1587 and Shiyu 1503 performed better than the other hybrids and were identified as excellent varieties across locations because of their outstanding performances according to a 2 -year observation. The comprehensive utilization of the AMMI model and GGE biplot can enable the scientific and objective judgment of the high yield, stability, and adaptability of tested maize hybrids and provides theoretical support for the rational layout of maize hybrids in the environments of Hebei Province.
\end{abstract}

Keywords: yield, stability, adaptability, AMMI model, GGE biplot

\section{Introduction}

Maize (Zea mays L.) is an important industrial, feed, and food crop in China and plays an important role in the national economy (Yue et al., 2018a). The three major maize-producing areas in China are northeast spring, southwest mountainous, and Huanghuaihai summer, which has the largest maize concentration. The wheat-maize double cropping system is the planting mode in this region which accounts for approximately $1 / 3$ of the planting area and output of the country and frequently experiences natural disasters, such as high winds, heavy rainfall, drought, mites, high temperatures, and low temperatures during the filling period (Zhang et al., 2015; Zhao and Yang, 2018). In addition, the continued occurrence of maize pests and diseases destabilizes the production from this area and results in a massive difference between the actual field yield and genetic yield potential of maize hybrids (Yue et al., 2018b). These problems have seriously hindered the healthy development of the maize industry. Breeding high-yielding and stable hybrids suitable for environmental conditions in various regions is necessary to achieve high and stable maize yields. 
The combined regional trial of crop varieties is an important form of national and provincial regional trial that has emerged in the past 2 years and is an inevitable outcome of the modern seed industry. The combined regional trial of maize hybrids is the comprehensive evaluation of the yield, adaptability, stress resistance, quality, and representativeness of newly cultivated hybrids according to standard specifications (Bao et al., 2017; Zhao et al., 2018). Combined regional trials are performed to screen out genotypes with excellent performance, determine the best adaptation areas for the tested varieties, and maximize the yield potential in accordance with local conditions. Discriminative analysis between locations is an important aspect of combined regional trials. The scientific and effective selection of locations and the improvement of screening services for new hybrids are difficult problems encountered by agricultural researchers (Zhang et al., 2016; Blanche and Myers, 2016).

Yield and other important agronomic traits of maize hybrids are represented by genotype $(\mathrm{G})$, environment $(\mathrm{E})$, and genotype main effects and genotype-environment interaction effects (GEI). The GEI effect occurs when different hybrids face different Es. $E$ affects $G$ because of the GEI effect, which in turn causes changes in different hybrids (Ma'ali, 2008; Abakemal et al., 2016). A high interaction effect degrades the stability of maize hybrids. In general, maize hybrids that exhibit high and stable yields under different environmental conditions have good adaptability, a large promotion value, and an outstanding productivity but poor stability in local areas. Genotypes with special adaptability also have a high production promotion. Therefore, understanding the connotation and essence of the interaction effect is helpful for studying the stability of maize yields and agronomic traits under different environmental conditions.

Agricultural researchers have proposed numerous research methods, including ANOVA (Lin et al., 1992), principal component analysis (Perkins, 1972), high stability coefficient (Berzsenyi and Dang, 2008), coefficient of variation (Döring and Reckling, 2018), additive main effects and multiplicative interaction (AMMI model) (Zobel et al., 1988), and genotype main effects and GEI effect (GGE) biplot (Yan et al., 2000), for the analysis of crop genotype and environment interaction. The AMMI model and the GGE biplot have been commonly used for GEI analysis. The AMMI model, also known as the additive main effect product interaction model, is the combination of ANOVA and principal component analysis for maximizing the interaction between $\mathrm{G}$ and $\mathrm{E}$ and separating the sum of product terms with different values from additive model interactions. This technique can also maximize assessment accuracy (Thillainathan and Fernandez, 2001; Dehghani et al., 2016). The results of AMMI model analysis can be intuitively and concisely expressed and interpreted, thus aiding the stability analysis of varieties and the screening of $\mathrm{G}$ with special GEI effects and providing valuable information for the breeding of special varieties adapted for a particular environment (Lal, 2012). Several scholars have used the AMMI model for the GEI analysis of crops, such as maize (Ndhlela et al., 2014), wheat (Sareen et al., 2012), rice (Suwaero and Nasrullah, 2011), millet (Bashir et al., 2014), barley (Bocianowski et al., 2019) and potato (Thiyagu et al., 2012). The genotype main effect plus GEI (GGE) biplotl method was first proposed by Yan to analyze the regional test data of wheat varieties (Yan et al., 2000). This method analyzes the data in the regional experiment in a 2D map, and the results only show the G effect and GEI related to variety evaluation. This technique has become an ideal tool for studying crop genotype stability and location discrimination (Kaya et al., 2006; Baxevanos et al., 2008; Laurie and Booyse, 2015; Rea et al., 2016; Dehghani et al., 2017). Nevertheless, any analytical method is 
imperfect and has its own shortcomings. The AMMI model mainly considers the interaction between $\mathrm{G}$ and $\mathrm{E}$. Comprehensively evaluating the $\mathrm{G}$ effect in the breeding and promotion of genotypes is necessary. Analysis results often focus on genotypes that are stable and high yielding or stable and low yielding while ignoring genotypes with high yields but poor stability and thus are subjected to certain restrictions during application (Akinwale et al., 2014). The GGE biplot reveals the GEI information in the form of maps and reflects the cultivar's environmental adaptability. Relying only on 2D plane mapping in the analysis will lead to a loss of a part of the GE's mutation information. Therefore, this approach has a certain risk. The AMMI model and the GGE biplot method can be combined for the regional trials of crop genotypes, to screen out genotypes with good yield and poor stability and apply them in specific regions, thus greatly improving the accuracy of results (Muthoni, 2015; Erdemci, 2018).

Here, the AMMI model and the GGE biplot were used to comprehensively evaluate the stability, adaptability, and discrimination in the Zhongcheng combined regional maize trial in Hebei province from 2016 to 2017. This work aims to provide a theoretical basis for the selection and utilization of maize hybrids in the Huanghuaihai summer maize area of China.

\section{Materials and methods}

Experimental data were derived from the Zhongcheng combined regional maize trial of Hebei Province, China. Thirteen hybrids from private and public companies were tested in 2016 and 2017, and Zhengdan 958 was used as a control hybrid. Information on the tested hybrids is shown in Table 1. The numbers of locations in 2016 and 2017 were 13 and 16, respectively. The latitude, longitude, altitude, and annual rainfall differed between locations as shown in Table 2.

\section{Experimental design}

Each location was designed by randomized complete block design (RCBD) with three repetitions. Each experimental plot contained 5 rows with dimensions of $6.7 \mathrm{~m}$ for each genotype, 6-8 rows were surrounded by protected areas, and 3 rows of each plot were harvested on time. The field management of each plot was slightly more intense than the field level and involved timely chemical weeding and pest control. Field management and measurements were completed on the same day in case of special weather. Integrated pest management methods, including the use of bait to trap rats. Thrips and armyworm are the most important pests in maize seedling stage, and the control measure is to use $4.5 \%$ high efficiency cypermethrin 15000 times liquid spray per hectare. The control of weeds is carried out in two stages. In the first stage, weeds are controlled by chemical agents (methalamin $3000 \mathrm{ml} / \mathrm{ha}$ plus $450 \mathrm{~kg} / \mathrm{ha}$ ) at preemergence stage. The second stage is to use $225 \mathrm{ml} / \mathrm{ha}$ of nitrocellulose at a concentration of $225 \mathrm{~kg} / \mathrm{ha}$ of nitrocellulose in the 3-5 leaves of the post-emergence stage. Both pre-emergence and post-emergence weeding are directed sprayed under windless conditions. The sowing date was carried out on $10^{\text {th }}-20^{\text {th }}$ of June of each location, and the harvest period was controlled from $1^{\text {th }}$ to $10^{\text {th }}$ of October during 20162017. Each location was reasonably arranged for fertilizer application according to the respective soil measurement conditions, $150-200 \mathrm{~kg} \mathrm{~N} \mathrm{ha}^{-1}$ and 100-130 kg $\mathrm{P}_{2} \mathrm{O}_{5} \mathrm{ha}^{-1}$ were applied at the time of sowing date. The plant height and ear position of the hybrid were investigated during the milk maturity period, and lodging and folding were 
investigated during the waxy stage. The traits of 100-grain weight, ear length, and kernel weight were investigated after harvest and the grain yield has been corrected for $14 \%$ moisture at each location.

Table 1. Basic information of the hybrids in the Zhongcheng maize combined regional trial in 2016-2017

\begin{tabular}{|c|c|c|c|c|}
\hline Hybrid & Abbreviation & $\begin{array}{c}\text { Growth } \\
\text { period }(d)\end{array}$ & Breeding institute & Year \\
\hline Jiyu 974 & J974 & 106 & $\begin{array}{c}\text { Institute of Cereal and Oil Crops, Hebei } \\
\text { Academy of Agriculture and Forestry Sciences } \\
\end{array}$ & 2016 \\
\hline Jiyu 610 & J610 & 108 & \begin{tabular}{|c|} 
Institute of Cereal and Oil Crops, Hebei \\
Academy of Agriculture and Forestry Sciences
\end{tabular} & 2016 \\
\hline Jiyu 906 & J906 & 106 & $\begin{array}{c}\text { Institute of Cereal and Oil Crops, Hebei } \\
\text { Academy of Agriculture and Forestry Sciences }\end{array}$ & 2016-2017 \\
\hline JL 658 & JL658 & 105 & Jifeng Seed Industry, Hebei & 2016 \\
\hline Xingyu 26 & $\mathrm{X} 26$ & 105 & $\begin{array}{c}\text { Xingtai Agricultural Science Research } \\
\text { Institute }\end{array}$ & 2016 \\
\hline Xingyu 375 & X375 & 108 & $\begin{array}{c}\text { Xingtai Agricultural Science Research } \\
\text { Institute }\end{array}$ & 2016 \\
\hline Hengyu 1587 & $\mathrm{H} 1587$ & 106 & $\begin{array}{c}\text { Dryland Farming Institute, Hebei Academy of } \\
\text { Agriculture and Forestry Sciences }\end{array}$ & 2016-2017 \\
\hline Hengyu 12 & $\mathrm{H} 12$ & 106 & $\begin{array}{c}\text { Dryland Farming Institute, Hebei Academy of } \\
\text { Agriculture and Forestry Sciences }\end{array}$ & 2016 \\
\hline Shiyu 1501 & S1501 & 108 & $\begin{array}{c}\text { Shijiazhuang Academy of Agricultural and } \\
\text { Forestry Sciences }\end{array}$ & 2016 \\
\hline Shiyu 1503 & S1503 & 107 & $\begin{array}{c}\text { Shijiazhuang Academy of Agricultural and } \\
\text { Forestry Sciences }\end{array}$ & 2016-2017 \\
\hline Cangkeyu 1 & $\mathrm{C} 1$ & 106 & $\begin{array}{l}\text { Cangzhou Academy of Agriculture and } \\
\text { Forestry Sciences }\end{array}$ & 2016 \\
\hline Tangyu 5115 & T5115 & 108 & $\begin{array}{c}\text { Tangshan Academy of Agricultural and } \\
\text { Forestry Sciences }\end{array}$ & 2016 \\
\hline Zhengdan $958 \mathrm{CK}$ & Z958 & 108 & $\begin{array}{c}\text { Henan Academy of Agriculture and Forestry } \\
\text { Sciences } \\
\end{array}$ & 2016-2017 \\
\hline RT 3321 & RT3321 & 107 & $\begin{array}{l}\text { Hebei Banghao Agricultural Development Co., } \\
\text { Ltd. }\end{array}$ & 2017 \\
\hline Cangyu 168 & C168 & 108 & $\begin{array}{c}\text { Cangzhou Academy of Agriculture and } \\
\text { Forestry Sciences }\end{array}$ & 2017 \\
\hline Cangyu 268 & C268 & 107 & $\begin{array}{c}\text { Cangzhou Academy of Agriculture and } \\
\text { Forestry Sciences }\end{array}$ & 2017 \\
\hline Hengyu 6084 & H6084 & 106 & \begin{tabular}{|c|} 
Dryland Farming Institute, Hebei Academy of \\
Agriculture and Forestry Sciences
\end{tabular} & 2017 \\
\hline Jiyu 202 & $\mathrm{~J} 202$ & 107 & $\begin{array}{c}\text { Institute of Cereal and Oil Crops, Hebei } \\
\text { Academy of Agriculture and Forestry Sciences }\end{array}$ & 2017 \\
\hline Jiyu 7176 & J7176 & 106 & $\begin{array}{c}\text { Institute of Cereal and Oil Crops, Hebei } \\
\text { Academy of Agriculture and Forestry Sciences }\end{array}$ & 2017 \\
\hline Tangyu 6925 & T6925 & 108 & $\begin{array}{c}\text { Tangshan Academy of Agricultural and } \\
\text { Forestry Sciences }\end{array}$ & 2017 \\
\hline Xingyu 1511 & $\mathrm{X} 1511$ & 106 & $\begin{array}{c}\text { Xingtai Agricultural Science Research } \\
\text { Institute }\end{array}$ & 2017 \\
\hline Xingyu 1799 & X1799 & 106 & $\begin{array}{c}\text { Xingtai Agricultural Science Research } \\
\text { Institute }\end{array}$ & 2017 \\
\hline
\end{tabular}


Table 2. Basic information of the locations and its code in the trials in 2016-2017

\begin{tabular}{c|c|c|c|c|c|c}
\hline Location & Abbreviation & Longitude E & Latitude N & Altitude (m) & $\begin{array}{c}\text { Annual rainfall } \\
(\mathbf{m m})\end{array}$ & Year \\
\hline Mancheng & $\mathrm{MC}$ & $114^{\circ} 48^{\prime}$ & $38^{\circ} 52^{\prime}$ & 137 & 547 & $2016-2017$ \\
Handan & $\mathrm{HD}$ & $114^{\circ} 54^{\prime}$ & $36^{\circ} 63^{\prime}$ & 55 & 515 & $2016-2017$ \\
Gaocheng & $\mathrm{GC}$ & $114^{\circ} 85^{\prime}$ & $38^{\circ} 02^{\prime}$ & 59 & 494 & $2016-2017$ \\
Dingxing & $\mathrm{DX}$ & $115^{\circ} 80^{\prime}$ & $39^{\circ} 20^{\prime}$ & 28 & 551 & $2016-2017$ \\
Shenzhou & $\mathrm{SZ}$ & $115^{\circ} 56^{\prime}$ & $38^{\circ} 01^{\prime}$ & 29 & 482 & $2016-2017$ \\
Botou & $\mathrm{BT}$ & $115^{\circ} 91^{\prime}$ & $38^{\circ} 09^{\prime}$ & 16 & 547 & $2016-2017$ \\
Luquan & $\mathrm{LQ}$ & $114^{\circ} 20^{\prime}$ & $38^{\circ} 05^{\prime}$ & 90 & 540 & $2016-2017$ \\
Zhaoxian & $\mathrm{ZX}$ & $114^{\circ} 76^{\prime}$ & $37^{\circ} 48^{\prime}$ & 42 & 351 & $2016-2017$ \\
Renxian & $\mathrm{RX}$ & $114^{\circ} 40^{\prime}$ & $37^{\circ} 15^{\prime}$ & 33 & 498 & $2016-2017$ \\
Longyao & $\mathrm{LY}$ & $114^{\circ} 46^{\prime}$ & $37^{\circ} 22^{\prime}$ & 35 & 524 & $2016-2017$ \\
Cangzhou & $\mathrm{CZ}$ & $116^{\circ} 49^{\prime}$ & $38^{\circ} 18^{\prime}$ & 78 & 581 & 2016 \\
Qingxian & $\mathrm{QX}$ & $116^{\circ} 79^{\prime}$ & $38^{\circ} 58^{\prime}$ & 6 & 618 & 2016 \\
Fengnan & $\mathrm{FN}$ & $118^{\circ} 08^{\prime}$ & $39^{\circ} 34^{\prime}$ & 20 & 675 & $2016-2017$ \\
Qianying & $\mathrm{QY}$ & $116^{\circ} 26^{\prime}$ & $38^{\circ} 21^{\prime}$ & 10 & 620 & 2017 \\
Houying & $\mathrm{HY}$ & $116^{\circ} 38^{\prime}$ & $38^{\circ} 44^{\prime}$ & 15 & 617 & 2017 \\
Luanxian & $\mathrm{LX}$ & $118^{\circ} 42^{\prime}$ & $39^{\circ} 45^{\prime}$ & 33 & 697 & 2017 \\
Langfang & $\mathrm{LF}$ & $116^{\circ} 42^{\prime}$ & $39^{\circ} 34^{\prime}$ & 27 & 554 & 2017 \\
Yongnian & $\mathrm{YN}$ & $114^{\circ} 38^{\prime}$ & $36^{\circ} 44^{\prime}$ & 48 & 583 & 2017 \\
\hline
\end{tabular}

\section{Data analysis}

\section{AMMI model}

The formula for the AMMI model is as follows:

$$
y_{g e}=\mu+\alpha_{g}+\beta_{e}+\sum_{n=1}^{N} \lambda_{n} \gamma_{g n} \delta_{e n}+\theta_{g e}
$$

where yge represents the yield of genotype $(g)$ in the environment $(e), \mu$ is the grand mean, $\alpha_{g}$ represents the average deviation of $g$ from $\mu, \beta_{e}$ represents the average deviation of $e$ from $\mu, \lambda_{n}$ is the nth eigenvalue of interaction effect principal component axis, $\gamma_{g n}$ is the $\mathrm{G}$ principal component score representing the nth principal component, $\delta_{e n}$ represents the environmental principal component score of the nth principal component, and $\theta_{g e}$ is the error term.

\section{GGE biplot method}

The yield and ear trait data in the regional trials of the Zhongcheng combined regional maize trial were compiled into a two-way table with $G$ and E. Each test value was the average value of each hybrid in the corresponding location, and the calculation formula is as follows:

$$
Y_{g e}-y_{e}=\lambda_{1} \xi_{g 1} \eta_{e 1}+\lambda_{2} \xi_{g 2} \eta_{e 2}+\varepsilon_{g e}
$$


where $Y_{g e}$ is the yield of genotype $g$ in environment $e$; $y_{e}$ is the yield performance of all varieties in environment $e ; \lambda_{1} \xi_{g 1} \eta_{e 1}$ and $\lambda_{2} \xi_{g 2} \eta_{e 2}$ represent the first and second principal component scores of genotype $g$ in the environment $e$, respectively; $\lambda_{1}$ and $\lambda_{2}$ are the eigenvectors of the first and second principal components, respectively; $\xi_{g 1}$ and $\xi_{g 2}$ are the first and second eigenvector scores of environment $e$, respectively; and $\varepsilon_{g e}$ represents the residuals in the model (Balestre et al., 2009). AMMI model and GGE biplot analyses were performed using DPSV18.0 edition (Tang and Zhao, 2013).

\section{Results}

\section{Ear traits and yield performance of maize hybrids}

\section{0 kernel weight}

As shown in Figure 1, in 2016, the average 100-kernel weight was $39.03 \mathrm{~g}$ for Xingyu 26 and $38.85 \mathrm{~g}$ for Hengyu 12. These values were significantly higher than that of the control hybrid Zhengdan 958. The 100-kernel weight of Shiyu 1501 had a minimum value of 31.89, which was significantly lower than that of Zhengdan 958.

In the 2017 Zhongcheng combined regional maize trial, the average 100-kernel weights of Xingyu 1799, Jiyu 7176, Hengyu 6084, Tangyu 6925 and Hengyu 1587 were $39.21,39.20,37.38,35.99$, and $35.89 \mathrm{~g}$, respectively. These values were significantly higher than that of Zhengdan 958. The average of 100-kernel weights of Jiyu 906, Jiyu 202, and RT3321 were lower than those of Zhengdan 958, but the differences between these values were not significant. The 100-kernel weights of other varieties were significantly lower than that of Zhengdan 958.

\section{Grain yield}

In the 2016 Zhongcheng combined regional maize trial, the highest average grain yield of Shiyu 1501 was $10.44 \mathrm{t} \mathrm{ha}^{-1}$. The average grain yields of Shiyu 1502 and Hengyu 1587 were 10.41 and $10.33 \mathrm{t} \mathrm{ha}^{-1}$, respectively, which ranked second and third, respectively. The highest average grain yields of Xingyu 26 and Jiyu 906 were 10.10 and $10.01 \mathrm{t} \mathrm{ha}^{-1}$, respectively. The average grain yields of the above hybrids increased significantly compared with those of the control hybrid Zhegndan 958. JL658 and the control Zhengdan 958 had the same yield, and the average grain yields of other hybrids were significantly reduced compared with those of the control.

In the 2017 Zhongcheng combined regional maize trial, the grain yields of Hengyu 1587, Shiyu 1503, Tangyu 6925 and Jiyu 906 were higher than those of Zhegndan 958 and were $10.53,10.50,10.40$, and $10.26 \mathrm{t} \mathrm{ha}^{-1}$, respectively. No significant differences existed between these varieties and Zhengdan 958. The yields of Hengyu 6084, Jiyu 202 and Xingyu 1511 were $10.14,10.12$, and $10.06 \mathrm{t} \mathrm{ha}^{-1}$, respectively, and were insignificantly lower than those of the control. The grain yield of the other varieties was significantly lower than that of Zhengdan 958.

\section{Grain weight per ear}

In 2016, Jiyu 974 had the highest average grain weight per ear of $167.96 \mathrm{~g}$, followed by Xingyu 375 (164.53 g) and Hengyu 1587. The average grain weight per ear of Xing yu 26 and Shiyu 1503 was 164.48 g. The average grain weights per ear of JL658 and Shiyu 1501 ranked fourth and seventh, respectively, and were insignificantly higher 
than those of the control. The average grain weights per ear of Jiyu 906, Hengyu 12, Tangyu 5115, and Cangkeyu 1 were lower than those of control hybrid. The average grain weight per ear of Cangkeyu 1 was the lowest (141.59 g) and was significantly different from that of Zhengdan 958.
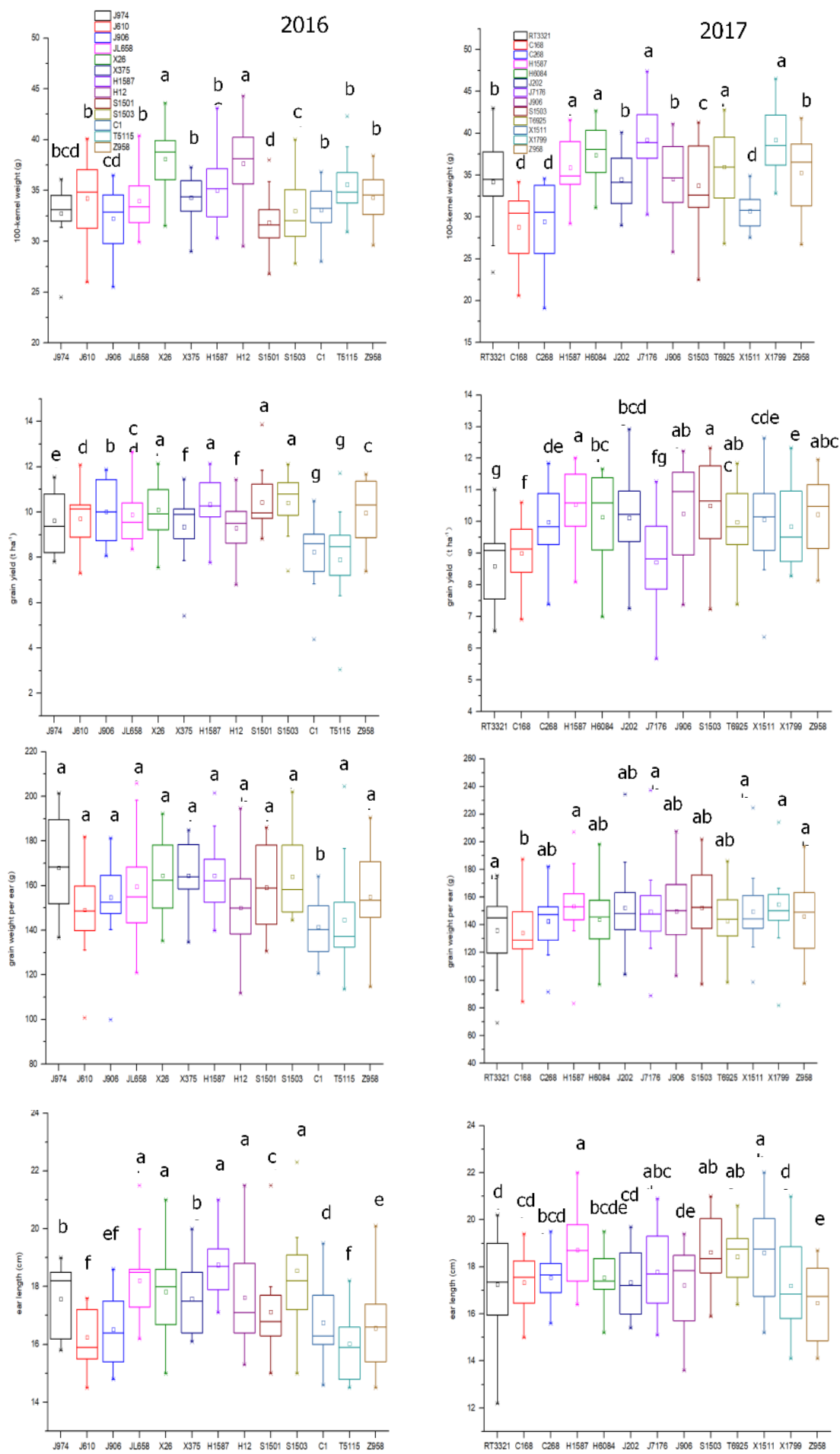

Figure 1. Traits average performance of maize hybrids in 2016-2017. The lowercase letters indicate significant difference at the 0.05 level 
In the 2017 test, Xingyu 1799 had the highest average grain weight per ear of 154.96 g, followed by Hengyu 1587 at $153.58 \mathrm{~g}$ and Jiyu 202 at $152.53 \mathrm{~g}$. The average grain weights per ear of Hengyu 6084, Tangyu 6925, Cangyu 268, RT3321, and Cangyu 168 were lower than that of the control hybrid Zhengdan 958.

\section{Ear length}

In 2016, Hengyu 1587 had the highest average ear length of $18.75 \mathrm{~cm}$, followed by Shiyu 1503 and JL 658. The average ear lengths of Xingyu 26, Hengyu 12, Shiyu 1501, and Cangkeyu 1 ranked fourth, fifth, sixth, and seventh, respectively, and were significantly higher than that of the control. The average ear lengths of Jiyu 906, Jiyu 610, and Tangyu 5115 were lower than that of the control. Significant difference was found between Jiyu 906 and Zhegndan 958 but not between the two hybrids and the control hybrid Zhengdan 958.

In 2017, the average ear length of all tested hybrids was higher than that of the control. Among them, Hengyu 1587 had the highest with $18.72 \mathrm{~cm}$, followed by Shiyu 1503, Xingyu 1511, and Jiyu 7176 with $18.62,18.61$, and $17.78 \mathrm{~cm}$, respectively. The differences between the above hybrids and the control were significant. The values for other hybrids did not reach significant levels.

\section{Analysis of AMMI model for various traits of maize hybrids}

\section{0-kernel weight}

Variance analysis for 100-kernel weight in 2016 showed that G, E, and GEI were extremely significant (Table 3). The squared sum of $\mathrm{G}$ accounted for $39.39 \%$ of the sum of squares. The square of the GEI had a total squared sum of $36.40 \%$. The ratio of square sum to the sum of squares for $\mathrm{E}$ was the smallest at $24.21 \%$. The interaction between $\mathrm{G}$ and GEI had a greater impact on 100-kernel weight than E. GEI was 1.5 times higher than $\mathrm{E}$, indicating that the former is crucial for the reasonable evaluation of 100-kernel weight. GEI was decomposed by the AMMI model, and the interaction effects of the first two principal component axes (PCA1 and PCA2) reached extremely significant levels. The square sums of PCA1 and PCA2 accounted for $33.01 \%$ and $21.34 \%$ of the sum of the interaction effects, respectively.

Variance analysis for 100-grain weight in the 2017 trial showed that the squared sum of $\mathrm{G}$ and $\mathrm{E}$ accounted for $36.19 \%$ and $35.66 \%$ of the sum of squares, respectively (Table 4). GEI squared accounted for $28.15 \%$ of the sum of squares, and G effects and E effects reached extremely significant levels. However, GEI effect was not significant. AMMI model analysis showed that the $P$-value of the GEI effect expressed by PCA 1 and PCA 2 was less than 0.01 and reached a very significant level, and the sum of the squares accounted for $31.02 \%$ and $20.77 \%$ of the square of the interaction effect.

\section{Grain yield}

Variance analysis of grain yield in the 2016 regional trial showed that the square sum of the E accounted for $46.67 \%$ of the total squared sum, that of GEI accounted for $31.06 \%$, and the square of $\mathrm{G}$ accounted for $22.26 \%$. G, E, and GEI effects reached a very significant level. E effect accounted for the largest proportion of the total effect. The variations of $\mathrm{E}$ and GEI were 2.10 times and 1.40 times that of genotype variation, 
respectively. Therefore, analyzing the stability of grain yield was necessary. PCA1 and PCA2 accounted for $41.04 \%$ and $23.55 \%$ of the sum of the GEI effects, respectively, and both reached extremely significant levels.

Table 3. Results of each trait analysis of variance and AMMI model analysis in 2016

\begin{tabular}{|c|c|c|c|c|c|c|c|}
\hline Items & Source of variation & $\begin{array}{l}\text { Degree of } \\
\text { freedom }\end{array}$ & $\begin{array}{c}\text { Sum of } \\
\text { squares }\end{array}$ & $\begin{array}{l}\text { Mean } \\
\text { square }\end{array}$ & $F$ value & $P$ value & $\begin{array}{l}\text { Percentage of } \\
\text { total sum of } \\
\text { squares }(\%)\end{array}$ \\
\hline \multirow{7}{*}{$\begin{array}{l}\text { 100-kernel } \\
\text { weight }\end{array}$} & Total & 168 & 1907.70 & 11.36 & & & \\
\hline & Genotype & 12 & 751.35 & 62.61 & $17.60^{* *}$ & $<0.0001$ & 39.39 \\
\hline & Environment & 12 & 461.95 & 38.50 & $10.82^{* *}$ & $<0.0001$ & 24.21 \\
\hline & $\begin{array}{c}\text { Genotype and } \\
\text { environment } \\
\text { interaction }(\mathrm{G} \times \mathrm{E})\end{array}$ & 144 & 694.39 & 4.82 & $1.36^{*}$ & 0.0431 & 36.40 \\
\hline & PCA1 & 23 & 229.21 & 9.97 & $2.80^{* *}$ & 0.0002 & 33.01 \\
\hline & PCA2 & 21 & 148.20 & 7.06 & $1.98^{*}$ & 0.0114 & 21.34 \\
\hline & Error & 119 & 423.33 & 3.56 & & & \\
\hline \multirow{7}{*}{ Grain yield } & Total & 168 & 433.20 & 2.58 & & & \\
\hline & Genotype & 12 & 96.45 & 8.04 & $14.53^{* *}$ & $<0.0001$ & 22.26 \\
\hline & Environment & 12 & 202.19 & 16.85 & $30.45^{* *}$ & $<0.0001$ & 46.67 \\
\hline & $\begin{array}{c}\text { Genotype and } \\
\text { environment } \\
\text { interaction }(\mathrm{G} \times \mathrm{E})\end{array}$ & 144 & 134.56 & 0.93 & $1.69^{* *}$ & 0.0016 & 31.06 \\
\hline & PCA1 & 23 & 55.22 & 2.40 & $4.34^{* *}$ & $<0.0001$ & 41.04 \\
\hline & PCA2 & 21 & 31.69 & 1.51 & $2.73^{* *}$ & 0.0003 & 23.55 \\
\hline & Error & 119 & 65.84 & 0.55 & & & \\
\hline \multirow{7}{*}{$\begin{array}{l}\text { Grain weight } \\
\text { per ear }\end{array}$} & Total & 168 & 76763.01 & 456.92 & & & \\
\hline & Genotype & 12 & 11106.85 & 925.57 & $4.94^{* *}$ & $<0.0001$ & 14.47 \\
\hline & Environment & 12 & 35443.89 & 2953.66 & $15.75^{* *}$ & $<0.0001$ & 46.17 \\
\hline & $\begin{array}{c}\text { Genotype and } \\
\text { environment } \\
\text { interaction }(\mathrm{G} \times \mathrm{E})\end{array}$ & 144 & 30212.27 & 209.81 & 1.12 & 0.2636 & 39.36 \\
\hline & PCA1 & 23 & 7530.63 & 327.42 & $1.75^{*}$ & 0.0286 & 24.93 \\
\hline & PCA2 & 21 & 5992.86 & 285.37 & 1.52 & 0.0827 & 19.84 \\
\hline & Error & 119 & 22317.71 & 187.54 & & & \\
\hline \multirow{7}{*}{ Ear length } & Total & 168 & 449.73 & 2.68 & & & \\
\hline & Genotype & 12 & 120.15 & 10.01 & $12.79^{* *}$ & $<0.0001$ & 26.72 \\
\hline & Environment & 12 & 169.18 & 14.10 & $18.02^{* *}$ & $<0.0001$ & 37.62 \\
\hline & $\begin{array}{c}\text { Genotype and } \\
\text { environment } \\
\text { interaction }(\mathrm{G} \times \mathrm{E})\end{array}$ & 144 & 160.41 & 1.11 & $1.42^{*}$ & 0.0233 & 35.67 \\
\hline & PCA1 & 23 & 53.34 & 2.32 & $2.96^{* *}$ & 0.0001 & 33.25 \\
\hline & PCA2 & 21 & 36.94 & 1.76 & $2.25 * *$ & 0.0033 & 23.03 \\
\hline & Error & 119 & 93.13 & 0.78 & & & \\
\hline
\end{tabular}


Table 4. Results of each trait analysis of variance and AMMI model analysis in 2017

\begin{tabular}{|c|c|c|c|c|c|c|c|}
\hline Items & Source of variation & $\begin{array}{l}\text { Degree of } \\
\text { freedom }\end{array}$ & $\begin{array}{l}\text { Sum of } \\
\text { squares }\end{array}$ & $\begin{array}{l}\text { Mean } \\
\text { square }\end{array}$ & $F$ value & $P$ value & $\begin{array}{c}\text { Percentage of } \\
\text { total sum of } \\
\text { squares }(\%)\end{array}$ \\
\hline \multirow{7}{*}{$\begin{array}{l}\text { 100-kernel } \\
\text { weight }\end{array}$} & Total & 207 & 5761.09 & 27.83 & & & \\
\hline & Genotype & 12 & 2084.88 & 173.74 & $26.05^{* *}$ & $<0.0001$ & 36.19 \\
\hline & Environment & 15 & 2054.31 & 136.95 & $20.54^{* *}$ & $<0.0001$ & 35.66 \\
\hline & $\begin{array}{c}\text { Genotype and } \\
\text { environment } \\
\text { interaction }(\mathrm{G} \times \mathrm{E})\end{array}$ & 180 & 1621.90 & 9.01 & $1.35^{*}$ & 0.0278 & 28.15 \\
\hline & PCA1 & 26 & 503.11 & 19.35 & $2.90^{* *}$ & $<0.0001$ & 31.02 \\
\hline & PCA2 & 24 & 336.86 & 14.04 & $2.10^{* *}$ & 0.0037 & 20.77 \\
\hline & Error & 152 & 1013.58 & 6.67 & & & \\
\hline \multirow{7}{*}{ Grain yield } & Total & 207 & 433.36 & 2.09 & & & \\
\hline & Genotype & 12 & 79.77 & 6.65 & $14.32^{* *}$ & $<0.0001$ & 18.41 \\
\hline & Environment & 15 & 208.74 & 13.92 & $29.97^{* *}$ & $<0.0001$ & 48.17 \\
\hline & $\begin{array}{c}\text { Genotype and } \\
\text { environment } \\
\text { interaction }(\mathrm{G} \times \mathrm{E})\end{array}$ & 180 & 144.86 & 0.80 & $1.73^{* *}$ & 0.0003 & 33.43 \\
\hline & PCA1 & 26 & 58.51 & 2.25 & $4.85^{* *}$ & $<0.0001$ & 40.39 \\
\hline & PCA2 & 24 & 33.12 & 1.38 & $2.97^{* *}$ & $<0.0001$ & 22.87 \\
\hline & Error & 152 & 70.58 & 0.46 & & & \\
\hline \multirow{7}{*}{$\begin{array}{l}\text { Grain weight } \\
\text { per ear }\end{array}$} & Total & 207 & 153812.95 & 743.06 & & & \\
\hline & Genotype & 12 & 8316.55 & 693.05 & $3.58^{* *}$ & 0.0001 & 5.41 \\
\hline & Environment & 15 & 99346.57 & 6623.10 & $34.24^{* *}$ & $<0.0001$ & 64.59 \\
\hline & $\begin{array}{c}\text { Genotype and } \\
\text { environment } \\
\text { interaction }(\mathrm{G} \times \mathrm{E})\end{array}$ & 180 & 46149.83 & 256.39 & $1.33^{*}$ & 0.0366 & 30.00 \\
\hline & PCA1 & 26 & 15342.13 & 590.08 & $3.05^{* *}$ & $<0.0001$ & 33.24 \\
\hline & PCA2 & 24 & 8937.10 & 372.38 & $1.93^{* *}$ & 0.0095 & 19.37 \\
\hline & Error & 152 & 29399.43 & 193.42 & & & \\
\hline \multirow{7}{*}{ Ear length } & Total & 207 & 581.60 & 2.81 & & & \\
\hline & Genotype & 12 & 92.25 & 7.69 & $9.01^{* * *}$ & $<0.0001$ & 15.86 \\
\hline & Environment & 15 & 296.43 & 19.76 & $23.15^{* *}$ & $<0.0001$ & 50.97 \\
\hline & $\begin{array}{c}\text { Genotype and } \\
\text { environment } \\
\text { interaction }(\mathrm{G} \times \mathrm{E})\end{array}$ & 180 & 192.92 & 1.07 & 1.26 & 0.0738 & 33.17 \\
\hline & PCA1 & 26 & 49.37 & 1.90 & $2.22^{* *}$ & 0.0015 & 25.59 \\
\hline & PCA2 & 24 & 47.94 & 2.00 & $2.34^{* *}$ & 0.0010 & 24.85 \\
\hline & Error & 152 & 129.76 & 0.85 & & & \\
\hline
\end{tabular}

Variance analysis for 2017 showed that G, E, and GEI accounted for $18.41 \%$, $48.17 \%$ and $33.43 \%$ of the total squared sum, respectively, and all of them reached extremely significant levels. The variations in E and GEI were 2.62 and 1.82 times 
higher than those of G. GEI was decomposed by the AMMI model, and the interaction information between PCA1 and PCA2 reached a very significant level. PCA1 and PCA2 accounted for $40.39 \%$ and $22.87 \%$ of the sum of square effects, respectively.

\section{Grain weight ear}

Variance analysis of regional trials in 2016 and 2017 showed that G and E differences reached extremely significant levels. GEI did not reach significant levels in 2016 but was significantly different in 2017. Environmental variation accounted for the majority of the variation in the 2-year regional trial. In 2016 and 2017, the sum of the squared environmental variances accounted for $46.17 \%$ and $64.59 \%$ of the total squared sum, respectively. The variations in GE and GEI were 2.72 and 5.55 times those of G effects, respectively. In 2016, PCA1 and PCA2 explained $44.77 \%$ and $52.61 \%$ of the square of the interaction effect. In 2016, the PCA1 interaction information reached a significant level, and PCA2 did not reach a significant level. PCA1 and PCA2 reached a very significant level in 2017.

\section{The ear length}

The variance analysis of ear length in 2016 showed that the squared sums of G, E, and GEI accounted for $26.72 \%, 37.62 \%$, and $35.67 \%$, respectively. G and E reached extremely significant differences. GEI effect reached a significant difference. AMMI model analysis showed that the square sum of PCA1 and PCA2 accounted for $33.25 \%$ and $23.03 \%$ of the sum of the square effects of the interaction, respectively. Both reached extremely significant levels. The AMMI model provided a thorough analysis of GEI effects.

Variance analysis revealed a significant difference between $G$ and E in 2017. The sum of the squares accounted for $15.86 \%$ and $50.97 \%$ of the total squared sum, respectively, and the square of the interactions accounted for $33.17 \%$ of the total square but did not reach a significant level. The results of AMMI model analysis showed that PCA1 and PCA2 accounted for $50.44 \%$ of the sum of squares of interactions and reached extremely significant differences.

\section{Adaptability analysis of tested varieties based on GGE biplot}

The GGE biplot visually represents the varieties with outstanding performance in different environments with different traits. Each of the "vertex" hybrid in the biplot is sequentially connected by a straight line to form a polygon, which is divided into a plurality of sectors from its origin. Each test environment is embedded in the sector. The "top angle" hybrid in each sector is the best-performing genotype in a certain environment (Yue et al., 2019a).

\section{0-kernel weight}

Adaptive analysis showed that the biplot map for 100-kernel weight in 2016 was divided into six sectors (Fig. 2-A1). Shenzhou, Fengnan, and Renxian were in the first sector. Xingyu 26 performed best in this sector. The remaining locations were divided into the second sector, and Hengyu 12 was the best performing hybrid. Adaptive analysis showed that the biplot map for 100-kernel weight in 2017, and the biplot map was divided into four sectors (Fig. 2-B1). The first sector included three locations in Shenzhou, Gaocheng, and Dingxing. Tangyu 6925 performed best in this sector. Hengyu 6084 had 
good adaptability in Zhaoxian, Botou, Qixian, and Luquan, and Hengyu 6084 showed the best performance in the second sector. The remaining locations were distributed in the third sector, wherein Xingyu 1799 and Jiyu 7176 showed the best performance. The fourth sector did not show a location, indicating that Cangyu 168, Cangyu 268, and Xingyu 1511 in this sector were not satisfactory in all locations.

\section{Grain yield}

The 13 locations of the 2016 regional trial were divided into three sectors (Fig. 2A2). Only Botou was located in the first sector, and Cangkeyu 1 showed the best performance. Zhaoxian, Longyao, Luquan, Mancheng, Dingxing, Cangzhou, Shenzhou, Gaocheng, Fengnan, and Qingxian were located in the second sector. Hengyu 1587 and Shiyu 1501 performed well in these locations. The third sector did not contain a location and included only Tangyu 5115. This result showed that Tangyu 5115 performed poorly in all locations. In 2017, the 16 plots of regional trial were divided into four sectors (Fig. 2-B2). Jiyu 202 exhibited outstanding performance in Botou, Shenzhou, Qianying, Gaocheng, Dingxing, and Longyao. Shiyu 1503 performed best in the remaining locations, and Hengyu 1587, Xingyu 1511, and Xingyu 1799 had strong adaptability.

\section{Grain weight per ear}

In 2016, 13 plots were divided into five sectors (Fig. 2-A3). Luquan, Cangzhou, Shenzhou, Qingxian, and Fengnan were classified as the first sector, and Hengyu 1587 had good adaptability in the above locations. The second sector had four locations, namely, Handan, Gaocheng, Mancheng, and Longyao. Jiyu 974 performed best in this sector. Renxian, Zhaoxian, and Botou were located in the third sector, and Xingyu 26 performed best. The fourth sector had only one location, and Cangkeyu 1 and Hengyu12 performed well in the Dingxing location. A location drop was not observed in the fifth sector, indicating that Tangyu 5115 and Jiyu 610 in this sector did not perform well in all locations. In 2017, 16 plots of the regional trial were divided into four sectors (Fig. 2-B3). The first sector only had one location in Zhaoxian, and RT3321 performed best in this sector. Botou, Dingxing, Langfang, Fengnan, Houying, and Luquan belonged to the second sector, and Xingyu 1799 had good adaptability in these locations. Mancheng, Yucheng, and Qianying belonged to the third sector, and Jiyu 7176 performed best. The remaining locations belonged to the fourth sector, and Jiyu 202 performed best.

\section{Ear length}

The adaptation analysis of the 2016 regional trial based on ear length showed that Shiyu 1503 performed best in the locations of Dingxing, Qingxian, Handan, and Zhaoxian. Hengyu 1587 had strong adaptability in Luquan, Zhangzhou, Yucheng, Shenzhou, Botou, Mancheng, and Renxian. Jiyu 974, Jiyu 906, Jiyu 610, Tangyu 5115, Shiyu 1501, and Cangkeyu 1 had unsatisfactory performances in all locations (Fig. 2$A 4)$. The results of the adaptation analysis of the 2017 regional trial based on ear length were obtained (Fig. 2-B4). Xingyu 1511 showed good adaptability in Langfang, Longyan, Renxian, Zhaoxian, Qixian, Shenzhou, Luquan, and Botou locations. Shiyu 1503 and Hengyu 1587 had good adaptability in different locations, such as Gaocheng, Dingxing, Handan, Mancheng, Houying, and Yongnian. The performance of all varieties in Qianying was not satisfactory, and the performances of Zhengdan 958 and Xingyu 1799 were not satisfactory in all the locations. 

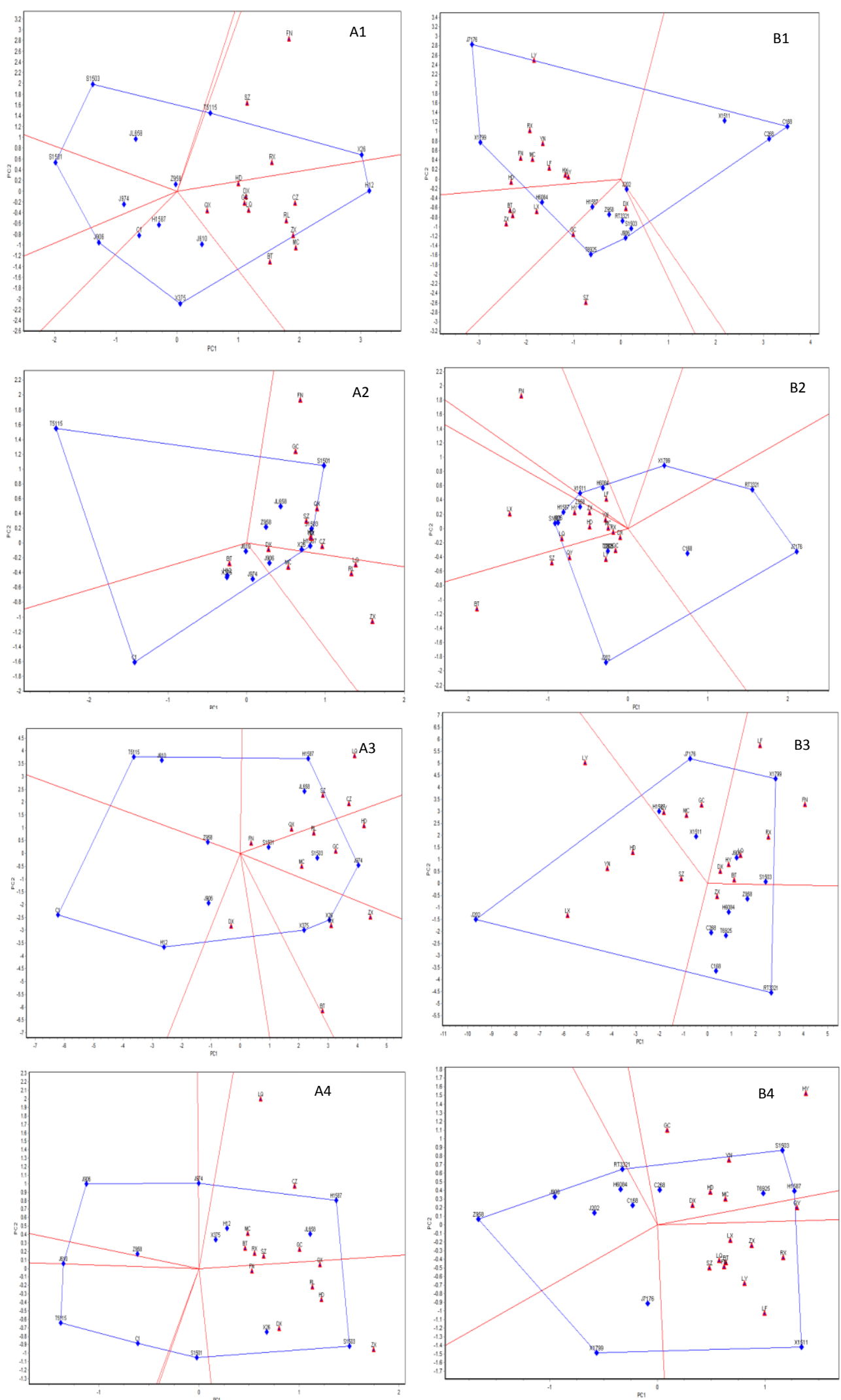

Figure 2. Adaptability analysis of maize hybrids based on GGE-biplot analysis. A: field data in 2016; B: field data in 2017; 1: 100-kernel weight; 2: grain yield; 3: grain weight per ear; 4: ear length (similarly hereinafter, the same below) 


\section{Analysis of the high yield and stability of the tested varieties based on GGE biplot}

The small diamond in Figure 3 represents the average environment, and the central straight line represents the average environmental axis. The genotypes in the double plot is perpendicular to the average environmental axis, and the high yield of the hybrids can be determined in accordance with the position and length of the vertical line. Vertical lines close to the average environment indicate that traits have high average values and are superior. Short vertical lines are indicative of small deviations from the average environmental axis and high trait stability (Sujay et al., 2012).

\section{0-kernel weight}

The analysis of 100-kernel weight and stability in the 2016 Zhongcheng combined regional maize trial revealed that Hengyu 12 had the highest weight, followed by Xingyu 26, Tangyu 5115, and Jiyu 610. Jiyu 906, Shiyu 1503, and Shiyu 1501 had poor performances in terms of 100-kernel weight. Hengyu 12, Zhengdan 958, Jiyu 974, Hengyu 1587, and Cangkeyu 1 had good stability, and Tangyu 5115, Xingyu 375, and Shiyu 1503 had poor performances (Fig. 3-A1). In the 2017 regional trial, Jiyu 7176 and Xingyu 1799 were closer to the average environment than other varieties. These two varieties had good 100-kernel weight performance. The performances of these varieties were followed by those of Hengyu 6084, Tangyu 6925, and Hengyu 1587. Xingyu 1511, Cangyu 268, and Cangyu 168 had low average 100-kernel weight. The stabilities of the 100-kernel weights of Jiyu 7176, Xingyu 1799, and Tangyu 6925 were poor, and those of the 100-kernel weights of Jiyu 202, Hengyu 6084, and Hengyu 1587 were good (Fig. 3-B1).

\section{Grain yield}

The grain yield in 2016 was analyzed (Fig. 3-A2). The yields of Shiyu 1501, Shiyu 1503, Hengyu 1587, and Xingyu 26 exceeded those of the control Zhengdan 958, Tang 5115, Cangkeyu 1, and Shiyu 1501, and the stability of the three varieties was significantly lower than that of the remaining varieties. In the 2017 regional trial, the yields of Shiyu 1503, Hengyu 1587, and Jiyu 906 were superior to those of Zhengdan 958. Cangyu 168, Cangyu 268, Hengyu 1587, and Shiyu 1503 had good stability (Fig. 3-B2).

\section{Grain weight per ear}

In the 2016 regional trial, the average grain weights per ear of Jiyu 974 were the highest, followed by those of Xingyu 26, Shiyu 1503, Xingyu 375, and Hengyu 1587. Cangkeyu1 had the lowest average grain weight per ear. The grain weight stabilities of Jiyu 974, Shiyu 1501, Shiyu 1503, and Zhengdan 958 were high, and those of other varieties were low (Fig. 3-A3). In the 2017 regional trial, the average grain weights of Jiyu 7176 were the highest, followed by those of Hengyu 1587, Xingyu 1799, Xingyu 1511, Jiyu 202, Jiyu 906, and Shiyu 1503. The average grain weights of the remaining varieties were lower than those of the control variety Zhengdan 958. The grain weight stabilities of Tangyu 6925, Xingyu 1511, Cangyu 268, and Hengyu 6084 were high, and those of Jiyu 202, Xingyu 1799, and Shiyu 1503 were poor (Fig. 3-B3). 

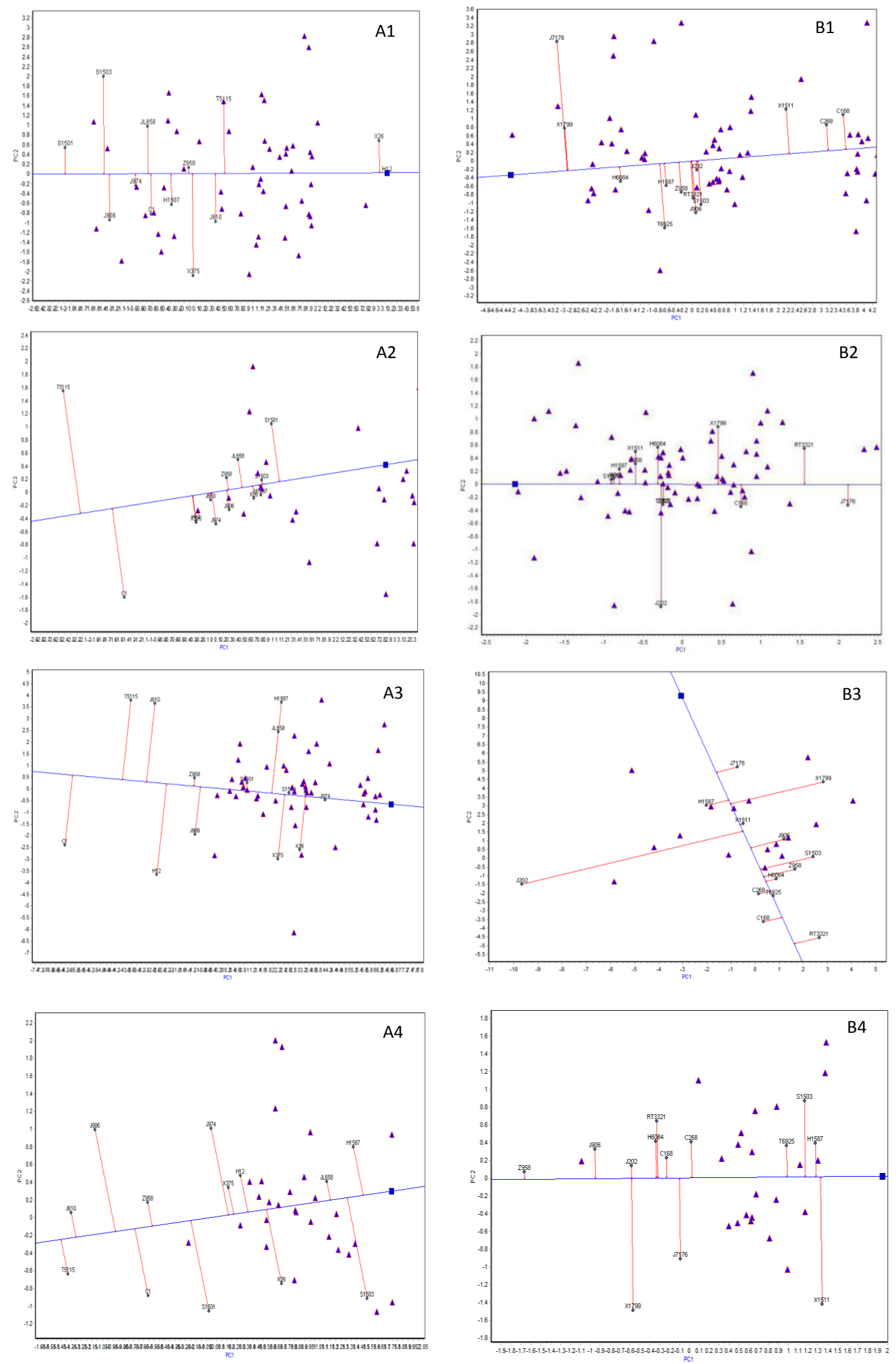

Figure 3. The yielding and stability of each trait of maize hybrids based on GGE-biplot analysis 


\section{Ear length}

In the 2016 regional trial, the average ear length of Hengyu 1587 was the highest, and those of Shiyu 1503 and JL658 were ranked second and third, respectively. Those of Cangkeyu 1, Jiyu 906, Jiyu 610, and Tang 5115 were lower than those of the control. The ear lengths of Jiyu 658, Xingyu 375, Hengyu 12, Hengyu 1587, Tangyu 5115, and Zhengdan 958 were stable, and those of other varieties were unstable (Fig. 3-A4). In the 2017 regional trial, the average ear lengths of Xingyu 1511, Hengyu 1587, Shiyu 1503, and Tangyu 6925 were high, and Zhengdan 958 had the lowest average ear length. Zhengdan 958, Jiyu 202, Cangyu 168, and Hengyu 1587 had high stability, and Shiyu 1503, Jiyu 7176, Xingyu 1511, and Xingyu 1799 had poor stability (Fig. 3-B4).

\section{Analysis of ideal varieties based on GGE biplot}

The GGE biplot can be used to visually and clearly determine the position of an ideal genotype. The ideal hybrid is the genotype with the highest average yield and the best stability in all test environments. The ideal hybrid is presented as the center of a multilayered concentric circle, and the pros and cons of the tested hybrids are judged on the basis of their distance from the ideal hybrid. Genotypes close to the center of the concentric circle have good performance, and those far from the center of the circle have poor performance (Kendal and Tekdal, 2019).

\section{0-kernel weight}

As shown in Figure 4-A1, Hengyu 12 and Xingyu 26 were closer to the center of the concentric circle than other hybrids. These two hybrids had high 100-kernel weights and were stable. Jiyu 906, Shiyu 1503, and Shiyu 1501 were far from the center of the concentric circle and had low 100-kernel weights and poor stability. As shown in Figure 4-B1, Xingyu 1799 was closest to the center of the concentric circle, indicating that this hybrid had a high kernel weight and good stability. Xingyu 1511, Cangyu 268, and Cangyu 168 were far from the center of the concentric circle and had low 100-grain weights and poor stability.

\section{Grain yield}

As illustrated in Figure 4-A2, Shiyu 1501, Shiyu 1503, and Hengyu 1587 were close to the center of the concentric circle, indicating that these genotypes had good yield and stability. Cangkeyu 1 and Tangyu 5115 were far from the center of the circle and had low yield and poor stability. Figure 4-B2 shows that Shiyu 1503, Jiyu 906, and Hengyu 1587 were closest to the center, indicating that these three varieties were high yielding and stable. Jiyu 202, Xingyu 1799, Cangyu 168, RT3321, and Xingyu 7176 were far from the center and had poor yield and stability.

\section{Grain weight per ear}

In 2016, Jiyu 974 was the closest to the center of concentric circles, indicating that its grain weight per ear was the highest and its stability was the best. The grain weight per ear of Cangkeyu 1 was opposite to that of Jiyu 974 and was the worst (Fig. 4-A3). In the 2017 regional trial, the grain weight per ear of Jiyu 7176 was the closest to the ideal value. Jiyu 7176 was a genotype with high grain weight per ear and good stability. The 
grain weights per ear of Hengyu 1587, Xingyu 1511, and Xingyu 1799 were ideal, and the comprehensive performances of Cangyu 168 and RT3321 were poor (Fig. 4-B3).
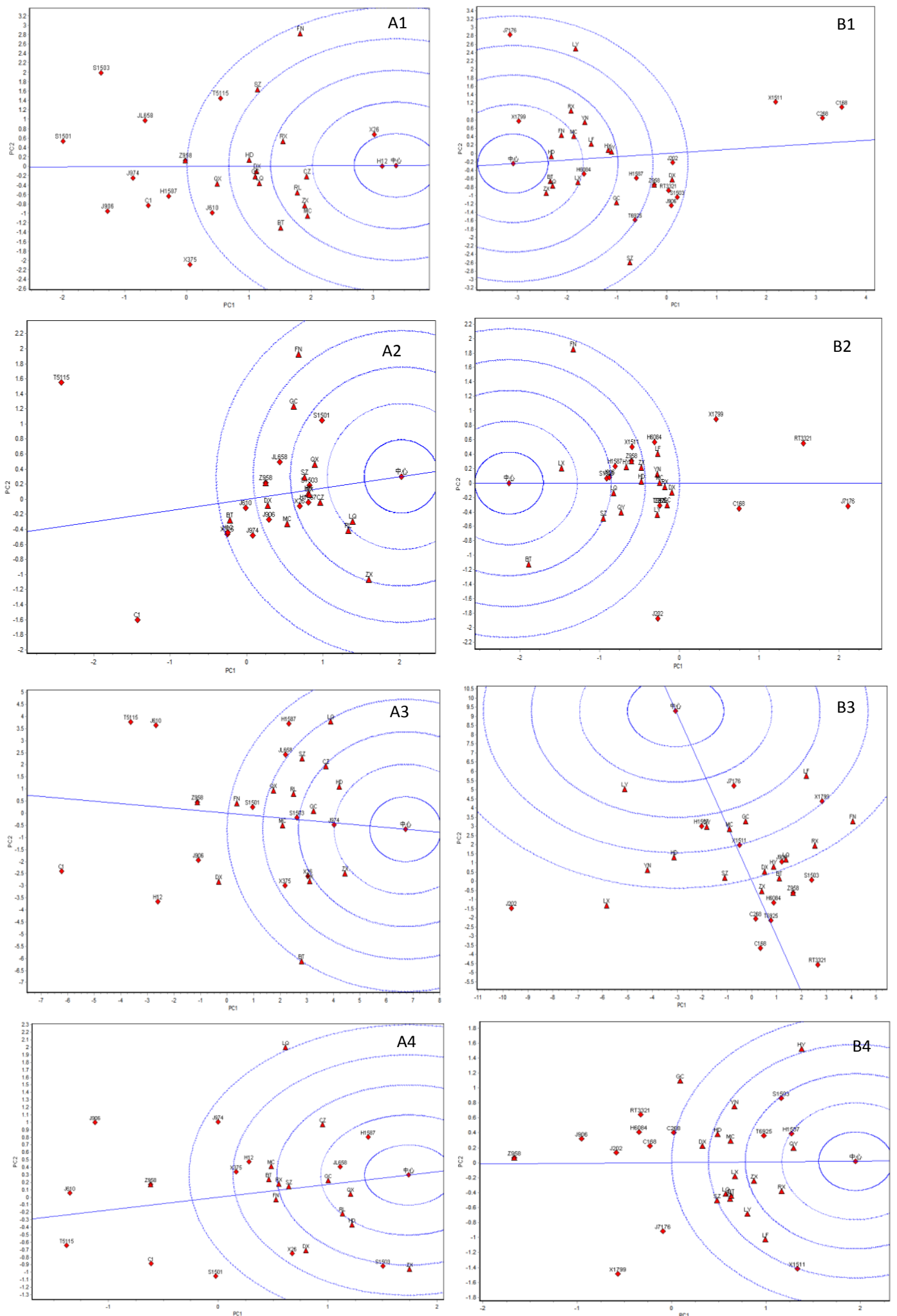

Figure 4. Comparisons of maize tested varieties with the ideal cultivar for each trait based on GGE biplot 


\section{Ear length}

It can be seen from Figure 4-A4 that the closest ideal genotypes in 2016 were Hengyu 1587 and JL 658, and the overall performance of the ear length was better. Genotypes such as Shiyu 1501, Cangkeyu 1, Zhengdan 958, Jiyu 906, Jiyu 610 and Tang 5115 had poor overall performance and are not ideal genotype. In the 2017 regional trial, Hengyu 1587 was the closest to the center of concentric circles, indicating that its overall ear length was excellent and belongs to the ideal genotype. Jiyu 202, Xingyu 1799, Jiyu 906 and Zhengdan 958 were far away from the center of concentric circles. Among them, Zhengdan 958 was the farthest from the center, and the overall performance of ear length was the worst (Fig. 4-B4).

\section{Discussion}

The traits of crop varieties are the results of G, E, and GEI. GEI directly affects the stability of varietal traits (Tekdal and Kendal, 2018). This study showed that in addition to 100-kernel weight, the effects of GEI on three agronomic traits were less than those of $\mathrm{E}$, but had significant effects on traits that were greater than those of G. The GEI effect of three traits, such as grain yield, grain weight per ear, and ear length in 20162017 was 1.3-5.5 times that of G (Balestre et al., 2009; Badu-Apraku et al., 2012; Yue et al., 2019b). This result is consistent with previous results. Trait differences caused by crop $\mathrm{G}$ changes and GEI effects must be considered in the regional trial analysis of crop varieties. Only by fully studying and utilizing the effects of GEI can breeding efficiency be considerably improved. This requires us to promote corn production and rationally distribute of varieties. First, the appropriate promotion area must be selected in accordance with local light and heat resources. Then, suitable varieties must be screened on the basis of characteristics. The influence of GEI on varietal traits must be emphasized (Kandus et al., 2010). The 2-year analysis of variance showed that the 100kernel weight of the tested varieties was less affected by external E and GEI. This indicates that 100-kernel weight is an inherent characteristic of the hybrid and is not easily affected by environmental changes. The expression of this trait is dominated by genotype effects.

The research and mastery of the variation in maize panicle traits are important bases for the breeding of high-yielding and stable maize hybrids and developing supporting cultivation techniques. Therefore, the stability analysis of important panicle traits and grain yield of maize genotypes can help fully understand the variation factors of varietal traits. The AMMI model can be used to calculate the AMMI stability value of the tested varieties in the form of a table and judge whether a genotye is high yielding and stable. The model focuses on GEI and enables the stability analysis of the genotypes. However, it fails to fully describe the adaptability of the varieties. The GGE biplot analysis compensates for this shortcoming. The GGE biplot map is a visual representation of the adapted area of the tested genotypes in a polygonal manner. This method focuses on the evaluation of varietal adaptability and yield (Erdemci, 2018; Malik et al., 2019). The GGE biplot analysis of the 2016 regional trial showed the adaptability of varieties on the basis of 100-kernel weight performance. Xingyu 26 and Hengyu 12 showed wide adaptability. The analysis of grain yield revealed that Hengyu 1587 and Shiyu 1501 had wide adaptability in 10 locations. The analysis of grain weight per ear revealed that Hengyu 1587, Jiyu 974, and Xingyu 26 had good adaptability in their respective regions. The analysis of ear length performance indicated that Shiyu 1503 and Hengyu 
1587 had wide adaptability. According to the 100-kernel weight adaptation analysis of the GGE biplot of the regional trial in 2017, Tangyu 6925, Hengyu 6084, Xingyu 199 and Jiyu 7176 had strong adaptability. The analysis of grain yield showed that Jiyu 202, Shiyu 1503, Hengyu 1587, Xingyu 1511, and Xingyu 1799 were widely adaptable. The analysis of grain weight per ear indicated that Xingyu 1799, Jiyu 7176, and Jiyu 202 had wide adaptability. Ear length analysis revealed that Shiyu 1503 and Xingyu 1511 had wide adaptability.

Ideal genotypes have high yield, stability, and wide adaptability in different environments. In fact, this is an ideal assumption and is rare in actual agricultural production. The high yield, stability, and adaptability of crop varieties are important indicators in breeding. Breeders tend to focus on genotypes with good yield stability but often overlook varieties with high yield and outstanding stability but limited adaptability (Jain et al., 2019). The rational use of maize hybrids should be based on the premise of high yield, and some varieties with good stability and adaptability should be selected. Selecting hybrids with good stability and adaptability from genotypes with poor yield is inadvisable. The stability of maize hybrids must be based on the premise of high yield. The regional trials of maize hybrids revealed that some genotypes are suitable for specific regions. For example, in 2016, Cangkeyu 1 exhibited the best grain yield in the environment of Botou but showed general performance at other locations. It had the highest grain weight per ear in the Dingxing environment. In 2017, the grain yield of Jiyu 202 ranked first in the environments of Botou, Shenzhou, Qianying, Gaocheng, Dingxing, and Longyao but had general overall performance in the remaining locations. Cangkeyu 1 and Jiyu 202 had special adaptability and can be planted in suitable areas. Therefore, we should not only pay attention to genotypes with perfect characteristics, but also to the identification and utilization of special adaptive hybrids in production practice (Rakshit et al., 2012; Yue et al., 2019). Through the analysis of the results of AMMI and GGE in this study, the two analytical methods had similar results considering the specific adaptability to environmental conditions. Due to the GEI, both AMMI and GGE can effectively explore the variability in multi environmental trials (Mets) data, and both methods have been shown to be approximately equivalent, thus screening for genotypes with the highest yield and high stability (Neisse et al., 2018; Kendal et al., 2019).

\section{Conclusion}

Multi environmental trials are an effective means to identify good or bad maize hybrids. The scientific evaluation of the stability, yield, and adaptability of maize genotypes is an important link before the promotion of hybrids. We evaluated important agronomic traits, such as 100-kernel weight, grain yield, grain weight per ear and ear length of maize hybrids using the AMMI model and GGE biplot analysis. We observed significant differences in agronomic traits between different genotypes and environments and significant or extremely significant GEIs. Combined with the performance of 2 years of experiments, Hengyu 1587 and Shiyu 1503 presented good comprehensive performance, while Cangkeyu 1 and Jiyu 202 showed special adaptability. The comprehensive application of AMMI and GGE biplot can more accurately and intuitively evaluate the high yield, stability and adaptability of each hybrid as well as the resolution and representativeness of each location. This research can provide valuable theoretical reference for the identification and promotion of new maize hybrids. 
Acknowledgements. This research was supported by the Appropriate Mechanization of New Summer Maize Variety Breeding, Demonstration and Promotion in North Huanghuaihai (Beijing-Tianjin-Hebei) (2017YFD0101202), the National Natural Science Foundation of China (31601386), the Special Fund for National System (Maize) of Modern Industrial Technology (nycytx-02), Science and Technology Support Program of Hebei Province (16226323D-X), the Special Fund for Agro-scientific Research in the Public Interest (201303002), the National Key Research and Development Program of China (2017YFD0701203), Shandong Key Research and Development Plan (Public Welfare Special Project, 2017GNC11103), A Project of Shandong Province Higher Educational Science and Technology Program (J18KA121).

\section{REFERENCES}

[1] Abakemal, D., Shimelis, H., Derera, J. (2016): Genotype-by-environment interaction and yield stability of quality protein maize hybrids developed from tropical-highland adapted inbred lines. - Euphytica 209(3): 757-769.

[2] Akinwale, R. O., Fakorede, M. A. B. Badu-Apraku, B. Oluwaranti, A. (2014): Assessing the usefulness of GGE biplot as a statistical tool for plant breeders and agronomists. Cereal Research Communications 42(3): 534-546.

[3] Badu-Apraku, B., Oyekunle, M., Obeng-Antwi, K., Osuman, A. S., Didjeira, A. (2012): Performance of extra-early maize cultivars based on GGE biplot and AMMI analysis. Journal of Agricultural Science 150(4): 473-483.

[4] Balestre, M., Von Pinho, R. G., Souza, J. C., Oliveira, R. L. (2009): Genotypic stability and adaptability in tropical maize based on AMMI and GGE biplot analysis. - Genetics and Molecular Research 8(4): 1311-1322.

[5] Bao, Y., Hoogenboom, G., Mcclendon, R. Vellidis, G. (2017): A comparison of the performance of the CSM-CERES-Maize and EPIC models using maize variety trial data. - Agricultural Systems 150: 109-119.

[6] Bashir, E. M. A., Ali, A. M., Ismail, M. I., Parzies, H. K., Haussmann, B. I. G. (2014): Patterns of pearl millet genotype-by-environment interaction for yield performance and grain iron (Fe) and zinc ( $\mathrm{Zn}$ ) concentrations in Sudan. - Field Crop Research 166: 82-91.

[7] Baxevanos, D., Goulas, C., Rossi, J., Braojos, E. (2008): Separation of cotton cultivar testing sites based on representativeness and discriminating ability using GGE biplots. Agronomy Journal 100: 1230-1236.

[8] Berzsenyi, Z., Dang, Q. L. (2008): Effect of various crop production factors on the yield and yield stability of maize in a long-term experiment. - Cereal Research Communications 36(1): 167-176.

[9] Blanche, S. B., Myers, G. O. (2016): Identifying discriminating locations for cultivar selection in Louisiana. - Crop Science 46: 946-949.

[10] Bocianowski, J., Warzecha, T., Nowosad, K., Bathelt, R. (2019): Genotype by environment interaction using AMMI model and estimation of additive and epistasis gene effects for 1000-kernel weight in spring barley (Hordeum vulgare L.). - Journal of Applied Genetics 60: 127-135.

[11] Dehghani, M. R., Majidi, M. M., Mirlohi, A., Saeidi, G. (2016): Study of genotype by environment interaction in tall fescue genotypes and their polycross progenies in Iran based on AMMI model analysis. - Crop Pasture Science 67: 792-799.

[12] Dehghani, M. R., Majidi, M. M., Saeidi, G., Mirlohi, A., Amiri, R., Sorkhilalehloo, B. (2017): Application of GGE biplot to analyse stability of Iranian tall fescue (Lolium arundinaceum) genotypes. - Crop Pasture Science 66: 963-972.

[13] Döring, T. F., Reckling, M. (2018): Detecting global trends of cereal yield stability by adjusting the coefficient of variation. - European journal Agronomy 99: 30-36.

[14] Erdemci, I. (2018): Investigation of genotype $\times$ environment interaction in chickpea genotypes using AMMI and GGE biplot analysis. - Turkish Journal of Field Crops 23(1): 20-26. 
[15] Jain, B. T., Sarial, A. K., Kaushik, P. (2019): Understanding G $\times$ E interaction of elite basmati rice (Oryza sativa L.) genotypes under north Indian conditions using stability models. - Applied Ecology and Environmental Research 17(3): 5863-5885.

[16] Kandus, M., Almorza, D. R., Salerno, J. C. (2010): Statistical models for evaluating the genotype-environment interaction in maize (Zea mays L.). - Phyton 79(1): 39-46.

[17] Kaya, Y., Akcura, M., Taner, S. (2006): GGE-biplot analysis of multi-environment yield trials in bread wheat. - Turkish Journal of Agriculture and Forestry 30: 325-337.

[18] Kendal, E., Tekdal, S. (2019): Proficiency of biplot methods (AMMI and GGE) in the appraisal of triticale genotypes in multiple environments. - Applied Ecology and Environmental Research 17(3): 5995-6007.

[19] Lal, R. K. (2012): Stability for oil yield and variety recommendations' using AMMI (additive main effects and multiplicative interactions) model in Lemongrass (Cymbopogon species). - Industrial Crops and Products 40: 296-301.

[20] Laurie, S. M., Booyse, M. (2015): Employing the GGE SREG model plus Elston index values for multiple trait selection in sweet potato. - Euphytica 204(2): 433-442.

[21] Lin, C. S., Butler, G., Hall, I., Nault, C. (1992): Program for investigating genotypeenvironment interaction. - Agronomy Journal 84(1): 121-124.

[22] Ma'ali, S. H. (2008): Additive mean effects and multiplicative interaction analysis of maize yield trials in South Africa. - South African Journal of Plant and Soil 25(4): 185193.

[23] Malik, W. A., Forkman, J., Hans-Peter, P. (2019): Testing multiplicative terms in AMMI and GGE models for multienvironment trials with replicates. - Theoretical and Applied Genetics 132: 2087-2096.

[24] Muthoni, J., Shimelis, H., Melis, R. (2015): Genotype $\times$ environment interaction and stability of potato tuber yield and bacterial wilt resistance in Kenya. - American Journal of Potato Research 92(3): 367-378.

[25] Neisse, A. C., Kirch, J. L., Hongyu, K. (2018): AMMI and GGE biplot for genotype $\times$ environment interaction: a medoid-based hierarchical cluster analysis approach for highdimensional data. - Biometrical Letters 55(2): 97-121.

[26] Ndhlela, T., Herselman, L., Magorokosho, C., Labuschagne, M. (2014): Genotype $\times$ environment interaction of maize grain yield using AMMI biplots. - Crop Science 54: 1992-1999.

[27] Perkins, J. M. (1972): The principal component analysis of genotype-environmental interactions and physical measures of the environment. - Heredity. 64: 51-70.

[28] Rakshit, S., Ganapathy, K. N., Gomashe, S. S. (2012): GGE biplot analysis to evaluate genotype, environment and their interactions in sorghum multi-location data. - Euphytica 185(3): 465-479.

[29] Rea, R., Sousa-Vieira, O. D., Díaz, A., Ramón, M., Briceño, R., George, J. (2016): Genotype-environment interaction, megaenvironments and two-table coupling methods for sugarcane yield studies in Venezuela. - Sugar Tech 18(4): 354-364.

[30] Sareen, S., Munjal, R., Singh, B. N., Verma, R. S., Meena, B. K. (2012): Genotype $\times$ environment interaction and AMMI analysis for heat tolerance in wheat. - Cereal Research Communications 45(2): 267-276.

[31] Sujay, R., Ganapathy, K. N., Gomashe, S. S., Rathore, A., Ghorade, R. B., Kumar, N., Ganesmurthy, K., Jain, S., Kamtar, M. Y., Sachan, J. S., Ambekar, S. S., Ranwa, B. R., Kanawade, D. G., Balusamy, M., Kadam, D., Sarkar, A., Tonapi, V. A., Patil, J. V. (2012): GGE biplot analysis to evaluate genotype, environment and their interactions in sorghum multi-location data. - Euphytica 185(3): 465-479.

[32] Suwaero, N. (2011): Genotype $\times$ environment interaction for iron concentration of rice in central java of Indonesia. - Rice Science 18: 75-78. 
[33] Tang, Q. Y., Zhang, C. X. (2013): Data Processing System (DPS) software with experimental design, statistical analysis and data mining developed for use in entomological research. - Insect Science 20: 254-260.

[34] Thillainathan, M., Fernandez, G. C. J. (2001): Sas applications for tai's stability analysis and ammi model in genotype $\times$ environmental interaction (GEI) effects. - Journal of Heredity 92(4): 367-371.

[35] Thiyagu, D., Rafii, M. Y., Mahmud, T. M. M., Latif, M. A. (2012): Stability analysis of sweetpotato (Ipomoea batatas Lam.) shoot tips yield for leafy vegetable across agroecologies using AMMI. - Australian Journal of Crop Science 6: 1522-1526.

[36] Tekdal, S., Kendal, E. (2018): AMMI model to assess durum wheat genotypes in multienvironment trials. - Journal of Agricultural Science and Technology 20(1): 153-156.

[37] Yan, W. K., Hunt, L. A., Sheng, Q., Szlavnics, Z. (2000): Cultivar evaluation and megaenvironment investigation based on the GGE biplot. - Crop Science 40: 597-605.

[38] Yue, H. W., Wei, J. W., Bu, J. Z., Li, J., Wang, X. G., Zheng, S. H., Xie, J. X., Chen, S. P., Peng, H. C., Jiang, X. W., Xie, J. L. (2019a): Comprehensive analysis of genotype by environment interaction of maize cultivars under multi-environment conditions in North China. - International Journal of Agriculture and Biology 21(6): 289-299.

[39] Yue, H. W., Bu, J. Z., Wei, J. W., Zhang, Y. L., Chen, S. P., Peng, H. C., Xie, J. L., Jiang, X. W. (2019b): Evaluation of the adaptability and stability of maize cultivars through GGE biplot analysis. - Fresenius Environmental Bulletin 28(9): 6719-6732.

[40] Yue, H. W., Li, Y., Li, C. J., Guo, A. Q., Chen, S. P., Peng, H. C., Xie, J. L., Jiang, X. W. (2018a): Grain filling characteristics of maize hybrids with different maturity periods. International Journal of Agriculture and Biology 20(7): 1650-1656.

[41] Yue, H. W., Bu, J. Z., Wei, J. W., Chen, S. P., Peng, H. C., Xie, J. X., Zheng, S. H., Jiang, X. W., Xie, J. L. (2018b): Effect of planting density on grain-filling and mechanized harvest grain characteristics of summer maize varieties in Huang-Huai-Hai plain. International Journal of Agriculture and Biology 20(6): 1365-1374.

[42] Zhang, X., Wang, Q., Xu, J., Gilliam, F. S., Tremblay, N., Li, C. (2015): In situ nitrogen mineralization, nitrification, and ammonia volatilization in maize field fertilized with urea in Huanghuaihai region of northern China. - Plos One 10(1): e0115649.

[43] Zhao, J., Yang, X. (2018): Average amount and stability of available agro-climate resources in the main maize cropping regions in China during 1981-2010. - Journal of Meteorological Research 32: 146-156.

[44] Zhao, Z. L., Liu, Z., Zhang, X. D., Zan, X. L., Yao, X. C., Wang, S. J., Ye, S. J., Li, S. M., Zhu, D. H. (2018): Spatial layout of multi-environment test sites: a case study of maize in Jilin province. - Sustainability. 10: 1424.

[45] Zhang, P. P., Song, H., Ke, X. W., Jin, X. J., Yin, L. H., Liu, Y. (2016): GGE biplot analysis of yield stability and test location representativeness in proso millet (Panicum miliaceum L.) genotypes. - Journal of Integrative Agriculture 15(6): 1218-1227.

[46] Zobel, R. W., Wright, M. J., Gauch, H. G. (1988): Statistical analysis of a yield trial. Agronomy Journal 80(3): 388-393. 